\title{
Patient satisfaction with TB care clinical consultations in Kampala: a cross sectional study.
}

\author{
Willy Ssengooba ${ }^{1}$, Bruce Kirenga $^{2}$, Catherine Muwonge ${ }^{3}$, Steven Kyaligonza ${ }^{3}$, Samuel Kasozi ${ }^{3}$, \\ Frank Mugabe ${ }^{3}$, Martin Boeree ${ }^{4}$, Moses Joloba ${ }^{5}$, Alphonse Okwera ${ }^{6}$ and PanACEA Consortium
}

\section{Department of Medical Microbiology Makerere University Kampala and}

Academic Medical Centre University of Amsterdam

2. Department of Medicine, Makerere University College of Health Sciences

3. National TB and Leprosy Program, Ministry of Health, Uganda

4. Department of Pulmonary Diseases, Radboud University Nijmegen Medical

5. Department of Microbiology, Makerere University College of Health Sciences

6. National Tuberculosis treatment unit, Mulago Hospital

\begin{abstract}
Background: Patient satisfaction towards care during encounter with clinicians is key for better treatment outcomes. We assessed patient satisfaction with TB clinical care consultations in Kampala, Uganda.

Methods: This was a facility-based cross sectional study done between September 2012 and February 2013 using qualitative method of data collection. Participants consecutively completed a pre-tested structured satisfaction questionnaire. A criteria of the rating as good; $>75 \%$ was considered acceptable, (50-75\%) as more effort is needed and $<50$ as unacceptable and require immediate action was used to categorize data for analysis using Epi-info 7.1.4.0.

Results: Of the 260 registered TB patients, 178(68.5\%) completed the questionnaire. Overall, $162(91.0 \%)$ were satisfied with the clinical consultation. Factors that contributed to high patient satisfaction, were: time spent with clinician (85.4\%), explanation of what was done (87.6\%), technical skills $(91.6 \%)$, personal manner of the clinician seen $(91.6 \%)$. Factors for low satisfaction were; waiting time before getting an appointment (61.8\%), convenience of location of consultation office (53.4\%), getting through to the office by phone (21.3\%) and length of time waiting at the office $(61.2 \%)$.

Conclusion: Tuberculosis patients in Kampala are satisfied with TB clinical care consultations. Addressing factors with low patient satisfaction may significantly impact on treatment outcome.
\end{abstract}

Keywords: Patient satisfaction, TB care clinical consultations, cross sectional study.

DOI: $h$ ttp://dx.doi.org/10.4314/abs.v16i4.28

Cite as: Ssengooba W, Kirenga B, Muwonge C, Kyaligonza S, Kasozi S, Mugabe F, Boeree M, Joloba M, Okwera A, PanACEA. Patient satisfaction with TB care clinical consultations in Kampala: a cross sectional study. Afri Health Sci. 2016;16(4): 1101-1108. http://dx.doi. org/10.4314/abs.v16i4.28

Background: Tuberculosis (TB) remains a major global health problem ${ }^{1}$. In 2013, there were estimated 9.0 million globally with (8.6-9.4 million) new tuberculosis (TB) cases annually. Those who died due to TB disease were 1.5 million of which $82 \%$ were from the 22 high burden Countries $^{2}$. In the same year, Uganda was estimated to have a TB incidence rate of 166/100,000 and TB mor-

\section{Corresponding author: \\ Willy Ssengooba BBS, \\ Department of Medical Microbiology \\ Makerere University Kampala \\ and Academic Medical Centre \\ University of Amsterdam \\ Email: willyssengooba@gmail.com}

tality rate of $11 / 100,000^{2}$. The burden of Multidrug Resistant TB (MDR-TB) in Uganda is estimated at 1.4\% and $12 \%$ among new and re-treatment TB cases respectively ${ }^{3}$.

There is a high level of treatment failure and growing threat of MDR-TB cases despite the fact that TB is curable ${ }^{4}$. Collective efforts between the treating clinician and TB patient are urgently needed in the fight against tuberculosis. Understanding whether patients are satisfied with the clinical care they receive during clinical consultation may be one of the key avenues to improve early patient presentation to the clinic for early diagnosis as well as adherence to treatment for better treatment outcome.

Patients who are satisfied with clinical consultations are more likely to return to clinics, in case of treatment fol- 
low-up, and to comply with treatment requirements. Studies have shown that, satisfied patients are more likely to utilize health services ${ }^{5}$, comply with medical treatment ${ }^{6}$, and continue with the health care providers ${ }^{7}$.

Directly Observed Therapy, Short-course (DOTS) is one of the main components of the global strategy against TB for the World Health Organization (WHO). This strategy has been followed by the Uganda National TB control program since $1998^{8}$ with slow decrease in TB incidence and mortality. The slow decrease may be attributed to several factors including policy, practices and challenges, experiences during health service delivery. Health care workers have been for long highlighted as the frontline team in the fight against TB, and interaction between patient and the clinician may significantly influence treatment outcome.

Previous studies have indicated that successful communication leads to greater adherence to treatment as well as treatment requirements. Communication between patient and treating clinician is vital, especially for the treatment that requires long-term follow-up, and it leads to better patient satisfaction and treatment results ${ }^{9-11}$. Furthermore, patients who are not given sufficient information about TB have been found to become TB treatment defaulters ${ }^{12,13}$.

We set up a study to understand patient satisfaction with TB clinical care consultations in preparation for new treatment trials among susceptible and potential multidrug resistant TB patients in Kampala.

\section{Methods}

Study setting: This was a facility-based cross sectional study nested within a study conducted to understand the epidemiology of tuberculosis in Kampala district, Uganda. The study employed qualitative method of data collection and analysis of secondary data. Patients were recruited into the study from the following TB diagnostic and treatment Units (DTUs) in Kampala district: Kisenyi health center, Kiruddu health center, Kawaala health Center, Kitebi health center, Kawempe health center, Kiswa health center and Mulago hospital.

Sampling: All TB patients, new and previously treated, registered between September 2012 and February 2013 were eligible for the study. Study participants were adults aged 18 and above attending participating DTUs. The sample size was calculated based on each health facility's workload and details are described elsewhere ${ }^{14}$. All eligible participants were considered in the current study. Trained research assistants reviewed TB laboratory and facility registers at study sites on daily basis to capture newly diagnosed patients and patients on treatment who were expected to return for clinic visits. After clinician's consultation, patients were requested to complete a pre-tested structured satisfaction questionnaire, which was administered in the patients' preferred language.

Measurement of outcome: Variables considered were; how long the patient waited to get an appointment, convenience of the location of the office, getting through to the clinician's office by phone, length of time of waiting at the office, time spent with the physician/health care professional that the patient saw, explanation to the patient of what was done to him/her.

In addition, patients' perceived technical skills (thoroughness, carefulness, competence) of the physician/health care professional he/she saw, patients' satisfaction with the personal manner (courtesy, respect, sensitivity, friendliness) of the person he/she saw and the overall satisfaction with the consultation visit. Patients were told to rate each variable as good, fair, or poor.

Data analysis: Raw data was reviewed by the quality assurance officer of the study and all inconsistencies were documented and resolved. Quality checked data was entered into excel database, cleaned and analysed using epi-info software version 7.1.4.0. Descriptive analysis (frequencies and percentiles) was conducted. The levels of patient satisfaction and their clinical demographics were analysed. Measurements of outcome for patient satisfaction were rated as good; $>75 \%$ and therefore was considered acceptable, $50-75 \%$ with more effort needed and $<50$ as unacceptable and therefore required immediate action, at $95 \%$ confidence interval.

Ethical considerations: Ethical approval was obtained from the Makerere University School of Biomedical Science Research and Ethics committee and from the Uganda National Council of Science and Technology. Each study participant was assigned a unique study number for identification. Participant's names were not used on any study related document. Study documents were kept under lock and key. All participants provided written informed consent. 


\section{Results}

\section{Clinical and social demographics}

A total 260 participants were eligible for the study of which 178 (68.5\%) completed the satisfaction questionnaire. Figure 1.

\section{Figure 1: Study population for patient satisfaction with TB clinical care consultation}

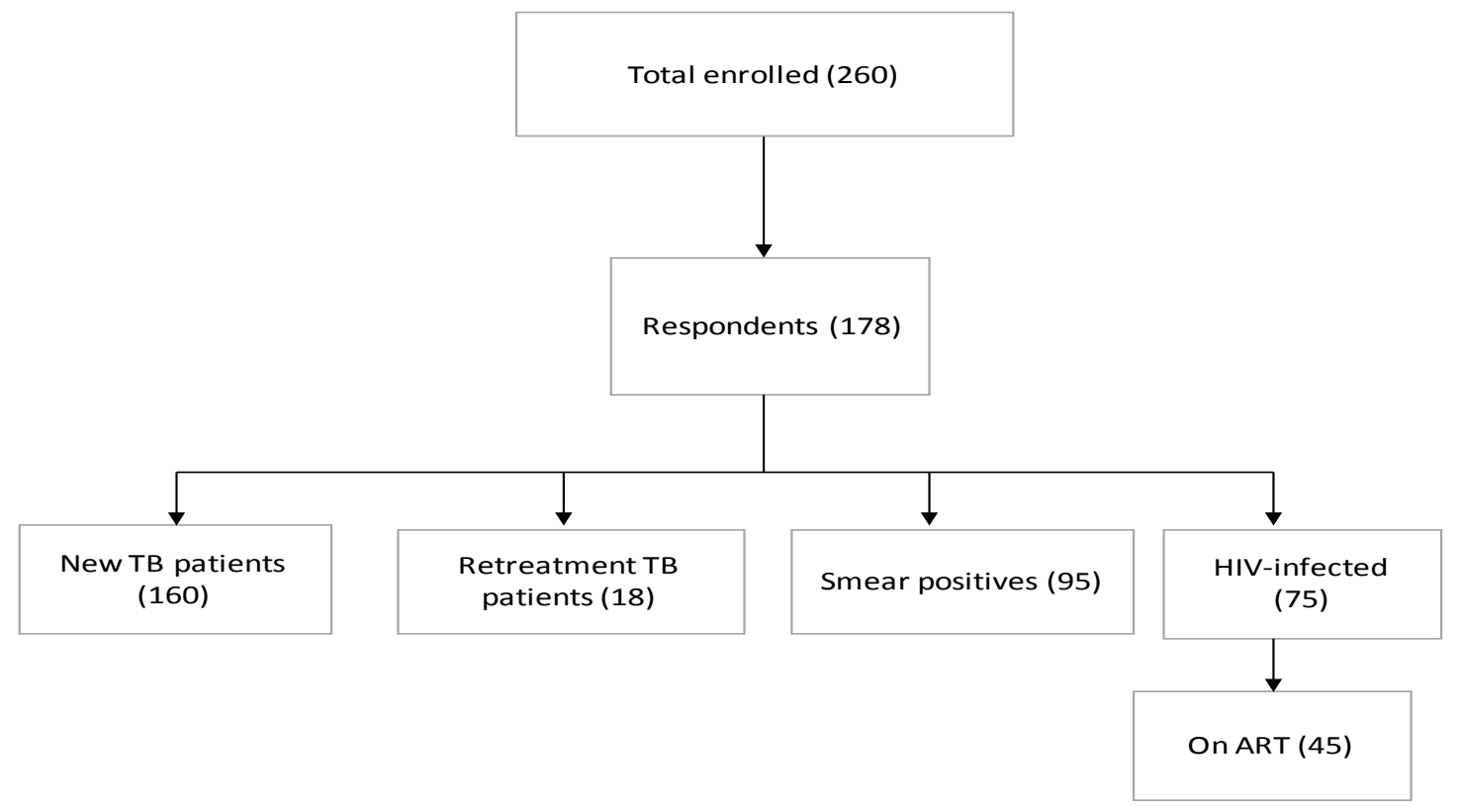

Key: ART= Antiretroviral Therapy

Female respondents were $102(57.3 \%)$ with majority of respondents $65(36.5 \%)$ indicating incomplete primary level as their highest level of education. Any resistance to TB drugs was $11(6.2 \%)$ and three $(1.6 \%)$ were found to be Multidrug Resistant-TB cases, Table 1

Table 1: Clinical and social demographics of participants $(n=178)$

\begin{tabular}{|l|c|c|}
\hline Characteristic & Parameter & $\mathbf{n}(\%)$ \\
\hline Sex & Female & $102(57.3)$ \\
\hline Age (years) & Male & $76(42.7)$ \\
\hline & $<20$ & $10(5.6)$ \\
\hline & $20-30$ & $97(54.5)$ \\
\hline & $31-40$ & $44(24.7)$ \\
\hline Highest level of education & $41-50$ & $22(12.4)$ \\
\hline & $>50$ & $5(2.8)$ \\
\hline & Incomplete primary & $65(36.5)$ \\
\hline & Incomplete secondary & $49(27.5)$ \\
\hline & Complete primary & $20(11.2)$ \\
\hline Drug Resistance & Complete secondary & $15(8.4)$ \\
\hline & Tertiary & $17(9.6)$ \\
\hline
\end{tabular}

Key: MDR-TB = Multi-Drug Resistant Tuberculosis

Patient satisfaction with TB care clinical consultations

Overall, 91.0\% (95\% CI; 85.8-94.8) of the respondents were satisfied with the TB clinical consultations. The key factors that contributed to high satisfaction were; time spent with clinician (85.4\%) (95\% CI; 79.3-90.2), explanation of what was done (87.6\%) (95\% CI; 81.9-92.1), technical skills (thoroughness, carefulness, competence) (91.6\%) (95\% CI; 86.5-95.2) and personal manner (courtesy, respect, sensitivity, friendliness) of the clinician seen 
91.6\%, (95\% CI; 86.5-95.2). Factors that contributed to low satisfaction were waiting time before getting appointment 61.8\% (95\% CI; 54.2-69.0), convenience of loca- tion of consultation office 53.4\% ( $95 \%$ CI; 45.8-60.9), getting through to the office by phone $21.3 \%$ (95\% CI; 15.6-28.1), length of time waiting at the office $61.2 \%$ ( 95\% CI; 53.7-68.4), Table 2.

Table 2; Overall TB patient satisfaction with TB care clinical consultations $(n=178)$

\begin{tabular}{|c|c|c|c|}
\hline \multirow[b]{2}{*}{ Question } & \multicolumn{3}{|c|}{ n (\%;95\% CI) } \\
\hline & Poor & Fair & Good \\
\hline How long you waited to get an appointment & $\begin{array}{c}25 \\
(14.0 ; 9.3-20.0)\end{array}$ & $\begin{array}{c}43 \\
(24.2 ; 18.1-31.1)\end{array}$ & $\begin{array}{c}110 \\
(61.8 ; 54.2-69.0)\end{array}$ \\
\hline Convenience of the location of the office & $\begin{array}{c}29 \\
(16.3 ; 11.2-22.6)\end{array}$ & $\begin{array}{c}54 \\
(30.3 ; 23.7-37.7)\end{array}$ & $\begin{array}{c}95 \\
(53.4 ; 45.8-60.9)\end{array}$ \\
\hline Getting through to the office by phone & $\begin{array}{c}121 \\
(68.0 ; 60.6-74.8)\end{array}$ & $\begin{array}{c}19 \\
(10.7 ; 6.60-16.2)\end{array}$ & $\begin{array}{c}38 \\
(21.3 ; 15.6-28.1)\end{array}$ \\
\hline Length of time waiting at the office & $\begin{array}{c}17 \\
(9.6 ; 5.7-14.9)\end{array}$ & $\begin{array}{c}52 \\
(29.2 ; 22.7-36.5)\end{array}$ & $\begin{array}{c}109 \\
(61.2 ; 53.7-68.4)\end{array}$ \\
\hline $\begin{array}{l}\text { Time spent with the physician/health care } \\
\text { professional you saw }\end{array}$ & $\begin{array}{c}6 \\
(3.40 ; 1.2-7.2)\end{array}$ & $\begin{array}{c}20 \\
(11.2 ; 7.0-16.8)\end{array}$ & $\begin{array}{c}152 \\
(85.4 ; 79.3-90.2)\end{array}$ \\
\hline Explanation of what was done for you & $\begin{array}{c}6 \\
(3.40 ; 1.2-7.2)\end{array}$ & $\begin{array}{c}16 \\
(9.0 ; 5.2-14.2)\end{array}$ & $\begin{array}{c}156 \\
(87.6 ; 81.9-92.1)\end{array}$ \\
\hline $\begin{array}{l}\text { Technical skills (thoroughness, carefulness, } \\
\text { competence) of the physician/health care } \\
\text { professional you saw }\end{array}$ & $\begin{array}{c}4 \\
(2.2 ; 0.6-5.7)\end{array}$ & $\begin{array}{c}11 \\
(6.3 ; 3.1-10.8)\end{array}$ & $\begin{array}{c}163 \\
(91.6 ; 86.5-95.2)\end{array}$ \\
\hline $\begin{array}{l}\text { The personal manner (courtesy, respect, } \\
\text { sensitivity, friendliness) of the person you } \\
\text { saw }\end{array}$ & $\begin{array}{c}1 \\
(0.6 ; 0.0-3.1)\end{array}$ & $\begin{array}{c}14 \\
(7.9 ; 4.4-12.8)\end{array}$ & $\begin{array}{c}163 \\
(91.6 ; 86.5-95.2)\end{array}$ \\
\hline The visit overall & $\begin{array}{c}3 \\
(1.7 ; 0.3-4.8)\end{array}$ & $\begin{array}{c}13 \\
(7.3 ; 3.9-12.2)\end{array}$ & $\begin{array}{c}162 \\
(91.0 ; 85.8-94.8)\end{array}$ \\
\hline
\end{tabular}

Among retreatment TB patients, the factors that contributed to low patient satisfaction were; convenience of location of consultation office $8(44.4 \%)$, none was satisfied with getting through to the office by phone and length of time waiting at the office $6(33.3 \%)$, Table 3.

Table 3; Patient satisfaction with TB care clinical consultations by TB treatment category

\begin{tabular}{|c|c|c|c|c|c|c|}
\hline \multirow[b]{2}{*}{ Question } & \multicolumn{3}{|c|}{$\begin{array}{c}\text { New N=160 } \\
n(\%)\end{array}$} & \multicolumn{3}{|c|}{$\begin{array}{c}\text { Retreatment } N=18 \\
n(\%)\end{array}$} \\
\hline & Poor & Fair & Good & Poor & Fair & Good \\
\hline $\begin{array}{l}\text { How long you waited to get an } \\
\text { appointment }\end{array}$ & $24(15.0)$ & $37(23.1)$ & $99(61.9)$ & $1(5.6)$ & $6(33.3)$ & $\begin{array}{c}11 \\
(61.1)\end{array}$ \\
\hline Convenience of the location of the office & $27(16.9)$ & $46(28.8)$ & $87(54.4)$ & $2(11.1)$ & $8(44.4)$ & $\begin{array}{c}8 \\
(44.4)\end{array}$ \\
\hline Getting through to the office by phone & $106(66.3)$ & $16(10.0)$ & $38(23.8)$ & $15(83.3)$ & $3(16.7)$ & 0 \\
\hline Length of time waiting at the office & $15(9.4)$ & $42(26.3)$ & $103(64.4)$ & $2(11.1)$ & $10(55.6)$ & $\begin{array}{c}6 \\
(33.3)\end{array}$ \\
\hline $\begin{array}{l}\text { Time spent with the physician/health } \\
\text { care professional you saw }\end{array}$ & $6(3.8)$ & $18(11.3)$ & $136(85.0)$ & 0 & $2(11.1)$ & $\begin{array}{c}16 \\
(88.9)\end{array}$ \\
\hline Explanation of what was done for you & $6(3.8)$ & $13(8.1)$ & $141(88.1)$ & 0 & $3(16.7)$ & $\begin{array}{c}15 \\
(83.3)\end{array}$ \\
\hline $\begin{array}{l}\text { Technicalskills (thoroughness, } \\
\text { carefulness, competence) of the } \\
\text { physician/health care professional you } \\
\text { saw }\end{array}$ & $4(2.5)$ & $11(6.9)$ & $145(90.6)$ & 0 & 0 & $\begin{array}{c}18 \\
(100)\end{array}$ \\
\hline $\begin{array}{l}\text { The personal manner (courtesy, respect, } \\
\text { sensitivity, friendliness) of the person } \\
\text { you saw }\end{array}$ & $1(0.6)$ & $14(8.8)$ & $145(90.6)$ & 0 & 0 & $\begin{array}{c}18 \\
(100)\end{array}$ \\
\hline The visit overall & $3(1.9)$ & $11(6.9)$ & $146(91.3)$ & 0 & $2(11.1)$ & $\begin{array}{c}16 \\
(88.9)\end{array}$ \\
\hline
\end{tabular}


On the other hand, those on ART, it was convenience through to the office by phone 4 (8.9\%), Table 4. of location of consultation office $22(48.9 \%)$ and getting

Table 4; Patient satisfaction with TB care clinical consultations among those on Antiretroviral Therapy $(n=45)$

\begin{tabular}{|c|c|c|c|}
\hline \multirow[b]{2}{*}{ Question } & \multicolumn{3}{|l|}{ n (\%) } \\
\hline & Poor & Fair & Good \\
\hline How long you waited to get an appointment & $4(8.9)$ & $11(24.4)$ & $30(66.7)$ \\
\hline Convenience of the location of the office & $3(6.7)$ & $20(44.4)$ & $22(48.9)$ \\
\hline Getting through to the office by phone & $37(82.2)$ & $4(8.9)$ & $4(8.9)$ \\
\hline Length of time waiting at the office & $4(8.9)$ & $16(35.6)$ & $25(55.6)$ \\
\hline Time spent with the physician/health care professional you saw & 0 & $6(13.3)$ & $39(86.7)$ \\
\hline Explanation of what was done for you & $1(2.2)$ & $4(8.9)$ & $40(88.9)$ \\
\hline $\begin{array}{l}\text { Technical skills (thoroughness, carefulness, competence) of the } \\
\text { physician/health care professional you saw }\end{array}$ & $1(2.2)$ & $1(2.2)$ & $43(95.6)$ \\
\hline $\begin{array}{l}\text { The personal manner (courtesy, respect, sensitivity, friendliness) of the } \\
\text { person you saw }\end{array}$ & 0 & $1(2.2)$ & $44(97.8)$ \\
\hline The visit overall & $1(2.2)$ & $2(4.4)$ & $42(93.3)$ \\
\hline
\end{tabular}

Among smear positive TB patients, only $23(24.2 \%)$ were satisfied with getting through to the office by phone, Table 5 .

Table 5; Patient satisfaction with TB care clinical consultations among smear positive TB patients $(\mathrm{n}=95)$

\begin{tabular}{|c|c|c|c|}
\hline \multirow[t]{2}{*}{ Question } & \multicolumn{3}{|c|}{ n (\%) } \\
\hline & Poor & Fair & Good \\
\hline How long you waited to get an appointment & $16(16.8)$ & $21(22.1)$ & $58(61.1)$ \\
\hline Convenience of the location of the office & $13(13.7)$ & $28(29.5)$ & $54(56.8)$ \\
\hline Getting through to the office by phone & $63(66.3)$ & $9(9.5)$ & $23(24.2)$ \\
\hline Length of time waiting at the office & $7(7.4)$ & $30(31.6)$ & $58(61.1)$ \\
\hline Time spent with the physician/health care professional you saw & $3(3.2)$ & $11(11.6)$ & $81(85.3)$ \\
\hline Explanation of what was done for you & $3(3.2)$ & $8(8.4)$ & $84(88.4)$ \\
\hline $\begin{array}{l}\text { Technical skills (thoroughness, carefulness, competence) of the } \\
\text { physician/health care professional you saw }\end{array}$ & $2(2.1)$ & $5(5.3)$ & $88(92.6)$ \\
\hline $\begin{array}{l}\text { The personal manner (courtesy, respect, sensitivity, friendliness) of } \\
\text { the person you saw }\end{array}$ & $1(1.1)$ & $11(11.6)$ & $83(87.4)$ \\
\hline The visit overall & $2(2.1)$ & $7(7.4)$ & $86(90.5)$ \\
\hline
\end{tabular}




\section{Discussion}

We have documented that overall, TB patients in Kampala are satisfied with TB clinical consultation visits. Access to phone consultations, waiting time before getting appointment, convenience of location of consultation office and length of time waiting at the clinician's office were the key factors that contributed to low patients satisfaction.

A study done in Ethiopia showed that patients' perceptions of health care provider interaction had a significant influence on patient satisfaction and adherence to TB treatment 15 . Interpersonal processes including perceived empathy, perceived technical competency, non-verbal communication, access to treatment point and patient enablement significantly influence patient satisfaction ${ }^{15-17}$. Furthermore, low level of dissatisfaction with the clinic and/or doctors has been documented as one of the risk factors for defaulting treatment among adult tuberculosis patients $^{18}$.

Improved communication may be overshadowed by practical problems such as waiting time to getting appointment to see a doctor or at the doctor's office and convenience of the location of the office to patients ${ }^{19-21}$, which may have significant influence on satisfaction ${ }^{22,23}$. In agreement with previous studies ${ }^{19,20}$, waiting time to get appointment to see the clinician or at the clinician's office, getting through to the clinician's office by phone and convenience of the location of the clinician's office were the key factors that negatively influenced TB patient satisfaction during clinical consultation. Good explanations of what was done to the patient, perceived technical skills ( thoroughness, carefulness, competence) of the clinician seen by the patient, the personal manner ( courtesy, respect, sensitivity, friendliness) of the clinician as observed by the patients may have contributed to overall patient satisfaction with the consultation visit by the patients as also documented by previous studies ${ }^{15,16}$. This could be due to increased training and staff sensitization on tuberculosis treatment and patient management conducted by the National TB program and several TB/HIV care stakeholders in Uganda ${ }^{24}$.

Interesting to note that patients were not satisfied and rated getting through to the clinician's office by phone as poor at $68 \%$ of the times. This is very important because about $64 \%$ of Ugandan adults who seek care own mobile phones ${ }^{25}$. A study done by Kunutsor, S. et al 2010 in Uganda, documented that mobile phones have a potential for use in resource-constrained settings to substantially improve the clinical management of HIV/AIDS25. Use of phones can be important for timely consultations, reminder for treatment visits as well as taking medication in terms of long term and strict treatment regimens like in TB and MDR-TB treatment ${ }^{26,27}$.

Co-infection with TB/HIV is likely to lead to a combination of treatment challenges including high drug burden, and if the patient is not satisfied at the start of treatment he/she is likely to be misinformed along the way and this may result into poor treatment outcome. Elbireer S, et al in 2011, indicated that defaulting among HIV-infected TB patients is influenced by health systems, staff factors, and patient misinformation, and that healtheducation on TB directed at patients combined with staff sensitization could help to improve adherence to anti TB treatment ${ }^{24}$. In our study, we have documented that none of the 18 retreatment patient and only $4 / 45(8.9 \%)$ of those on ART were satisfied with access to clinician's office by phone. This is a vital area that require urgent attention as these patient are overburdened with the treatment and are more likely to lose hope of being cured or getting better and may end up becoming drug resistant than those who are just starting the treatment. Therefore, efforts for reliable and timely patient-clinician consultations are much needed. Improved communication including access to clinician's office and clinicians accessing patients by phone is likely to improve information sharing and treatment outcome $e^{12,13}$.

This study had some limitations. We conducted the study over one quarter of the reporting year. There may be differences in the patients who reported to the health facilities during other times. The study being cross-sectional, we had less representation of some groups of patients like HIV-infected and retreatment category. This may not offer a complete picture in those categories of patients. However, being that we studied patients from several TB care clinics all-over Kampala district, this is not likely to significant affect our conclusions. Furthermore, the participating clinics and the participants were mainly from urban areas, more studies with participants from rural areas are recommended. 
Our findings among TB patients in Kampala shows that patients are satisfied with clinical consultations. We further highlight that the major areas affecting patient satisfaction are logistical and practical challenges. We therefore highly advocate for improvement in areas of waiting time in the treatment access chain, convenience of the consultation office and access of clinician's office by phone. This is likely to increase patient satisfaction with the clinical consultations and positively influence TB treatment outcomes.

\section{Competing interests}

All authors declare no competing interests.

\section{Author contributions}

Alphonse Okwera, Moses Joloba, Bruce Kirenga, Willy Ssengooba, Martin Boeree and Catherine Magezi wrote the study protocol. Stephen Kyaligonza collected data, Alphonse Okwera, Martin Boeree and Moses Joloba obtained funding for the study. Willy Ssengooba wrote the first manuscript draft. All authors participated in study analysis and manuscript preparation.

\section{Acknowledgements}

The authors would like to acknowledge the contribution made by the research assistants and health workers at the recruitment sites.

\section{Funding}

This study was funded under the PanACEA Consortium

\section{References}

1. World Health Organization. 2013. Global tuberculosis report. Geneva WHO/HTM/TB/ 2013.11. World Health Organization G, Switzerland: http://www.who. int/tb/publications/global_report/en/.

2. World Health Organization. Global tuberculosis report 2014. http://apps.who.int/iris/bitstre am/10665/137094/1/9789241564809_eng.pdf Accessed September 26-2015.

3. Lukoye D, Adatu F, Musisi K, et al. Anti-tuberculosis drug resistance among new and previously treated sputum smear-positive tuberculosis patients in Uganda: results of the first national survey. PloS one. 2013; 8: e70763. 4. World Health Organization. 2010. Multidrug and extensively drug-resistant tuberculosis (M/XDRTB): global report on surveillance and response. Ge- neva SW, 2010; http://whqlibdoc.who.int/publications/2010/9789241599191_eng.pdf.

5. Larsen DE and Rootman I. Physician role performance and patient satisfaction. Social science \& medicine. 1976; 10: 29-32.

6. Kincey J, Bradshaw P and Ley P. Patients' satisfaction and reported acceptance of advice in general practice. The Journal of the Royal College of General Practitioners. 1975; 25: 558-66.

7. Agerton TB, Valway SE, Blinkhorn RJ, et al. Spread of strain W, a highly drug-resistant strain of Mycobacterium tuberculosis, across the United States. Clinical infectious diseases : an official publication of the Infectious Diseases Society of America. 1999; 29: 85-92; discussion 3-5.

8. Adatu F, Odeke R, Mugenyi M, et al. Implementation of the DOTS strategy for tuberculosis control in rural Kiboga District, Uganda, offering patients the option of treatment supervision in the community, 1998-1999. The international Journal of tuberculosis and lung disease : the official journal of the International Union against Tuberculosis and Lung Disease. 2003; 7: S63-71.

9. Farin E. Patient-provider communication in chronic illness: current state of research in selected areas]. Die Rehabilitation. 2010; 49: 277-91.

10. Dibbelt S, Schaidhammer M, Fleischer C and Greitemann B. Patient-doctor interaction in rehabilitation: the relationship between perceived interaction quality and long-term treatment results. Patient education and counseling. 2009; 76: 328-35.

11. Bredart A, Bouleuc C and Dolbeault S. Doctor-patient communication and satisfaction with care in oncology. Current opinion in oncology. 2005; 17: 351-4.

12. Castelnuovo B. A review of compliance to anti tuberculosis treatment and risk factors for defaulting treatment in Sub Saharan Africa. African health sciences. 2010; 10: 3204.

13. Muture BN, Keraka MN, Kimuu PK, Kabiru EW, Ombeka VO and Oguya F. Factors associated with default from treatment among tuberculosis patients in Nairobi province, Kenya: a case control study. BMC public bealth. 2011; 11: 696.

14. Kirenga BJ, Ssengooba W, Muwonge C, et al. Tuberculosis risk factors among tuberculosis patients in Kampala, Uganda: implications for tuberculosis control. BMC public health. 2015; 15: 13.

15. Nezenega ZS, Gacho YH and Tafere TE. Patient satisfaction on tuberculosis treatment service and adherence 
to treatment in public health facilities of Sidama zone, South Ethiopia. BMC health services research. 2013; 13: 110. 16. Birhanu Z, Assefa T, Woldie M and Morankar S. Determinants of satisfaction with health care provider interactions at health centres in central Ethiopia: a cross sectional study. BMC health services research. 2010; 10: 78 .

17. Shargie EB and Lindtjorn B. Determinants of treatment adherence among smear-positive pulmonary tuberculosispatients in Southern Ethiopia. PLoS medicine. 2007; 4: e37.

18. Rutherford ME, Hill PC, Maharani W, Sampurno H and Ruslami R. Risk factors for treatment default among adult tuberculosis patients in Indonesia. The international journal of tuberculosis and lung disease : the official Journal of the International Union against Tuberculosis and Lung Disease. 2013; 17: 1304-9.

19. Girma A, D HM and Deribe K. Quality of tuberculosis care in six health facilities of Afar Region, Ethiopia. Ethiopian Medical Journal. 2010; 48: 195-202.

20. Palha PF, da Silva LM, Wysocki AD, et al. [Access to healthcare services for tuberculosis: analysis of patient satisfaction]. Revista da Escola de Enfermagem da US P. 2012; 46: 342-8.

21. Gemmell HA and Hayes BM. Patient satisfaction with chiropractic physicians in an independent physicians' association. Journal of Manipulative and Physiological Therapeutics. 2001; 24: 556-9.
22. Shilling V, Jenkins V and Fallowfield L. Factors affecting patient and clinician satisfaction with the clinical consultation: can communication skills training for clinicians improve satisfaction? Psycho-oncology. 2003; 12: 599-611.

23. Brown JB, Boles M, Mullooly JP and Levinson W. Effect of clinician communication skills training on patient satisfaction. A randomized, controlled trial. Annals of Internal Medicine. 1999; 131: 822-9.

24. Elbireer S, Guwatudde D, Mudiope P, Nabbuye-Sekandi $\mathrm{J}$ and Manabe YC. Tuberculosis treatment default among HIV-TB co-infected patients in urban Uganda. Tropical Medicine \& International Health: TM \& IH. 2011; 16: 981-7.

25. Kunutsor S, Walley J, Katabira E, et al. Using mobile phones to improve clinic attendance amongst an antiretroviral treatment cohort in rural Uganda: a cross-sectional and prospective study. AIDS and behavior. 2010; 14: 1347-52.

26. Elangovan R and Arulchelvan S. A Study on the Role of Mobile Phone Communication in Tuberculosis DOTS Treatment. Indian Journal of Community Medicine: official publication of Indian Association of Preventive \& Social Medicine. 2013; 38: 229-33.

27. Lei X, Liu Q, Wang H, Tang X, Li L and Wang Y. Is the short messaging service feasible to improve adherence to tuberculosis care? A cross-sectional study. Transactions of the Royal Society of Tropical Medicine and Hygiene. 2013; 107: 666-8. 